\title{
Motivations for BPM Adoption: Initial Taxonomy based on Online Success Stories
}

\author{
Renata Gabryelczyk \\ University of Warsaw \\ Faculty of Economic Sciences \\ ul. Długa $44 / 50$, \\ 00-241 Warszawa, Poland \\ Email: r.gabryelczyk@wne.uw.edu.pl
}

\author{
Aneta Biernikowicz \\ University of Warsaw \\ Faculty of Management \\ ul. Szturmowa $1 / 3$ \\ 02-678 Warszawa, Poland \\ Email: abiernikowicz@wz.uw.edu.pl
}

\begin{abstract}
The main aim of this research in progress is to develop an initial taxonomy of motivations underlying BPM (Business Process Management) adoption in organizations. This initial study is based on the analysis of 75 customer cases and success stories published on-line by BPM system vendors and BPM consulting companies. We used the mixed conceptual/empirical approach to taxonomy development basing the empirical analysis on descriptive data-coding canon. As the result of our research we present an initial taxonomy of the motivations for the adoption and use of BPM that consists of three dimensions: the organizational scope of a BPM initiative (enterprise-wide, process-focused or task oriented); presence (or not) of the information technology component; and, the importance of external versus internal drivers motivating a BPM initiative. Proposed initial taxonomy will be developed in further research and will serve to link the motivation to change with the expected benefits of BPM adoption.
\end{abstract}

\section{INTRODUCTION}

A ny organization making a decision about the adoption of Business Process Management (BPM) is guided by their specific motivations. These motivations are understood as the main reasons why organizations take BPM initiatives as a set of arguments used to support a decision concerning BPM implementation. The motivations behind the justification of organizational change are an indispensable element of every business case [1]. It is these motivations that most often reflect the benefits of BPM adoption [2]. In this study, the term "motivation" is related to its goals and expected benefits being the starting point for the decision to adopt BPM.

Although research generally confirms that individual motivations of employees are translated into the performance of the entire organization [3-5], studies on motivations for BPM adoption are virtually non-existent.

For the purpose of better understanding, analysis and use in future studies, motivations should be organized and classified by groups. In this study, we plan to develop an initial taxonomy of motivations which, according to the literature, can serve as a form of classification and as " $a$ fundamental mechanism for organizing knowledge” [6, pp.
11-12]. Taxonomies help to arrange concepts, to perceive the relations between concepts and to draw conclusions from them. Taxonomies also reduce complexity, which is why they are useful and important for both research and management practice $[6,7]$.

In our study, we will use the methodology for taxonomy development proposed by Nickerson et al. [6] that is established in the field of Information Systems. However, it will be the first time applied in BPM research.

To develop an initial taxonomy of BPM motivations, we will use secondary data from BPM case studies and success stories published on-line. We believe that the identification and initial taxonomy of BPM motivational factors will bring a new and original contribution not only to BPM research but also to the practice of the planning of BPM adoptions.

This paper will be organized as follows: firstly, the research background will be presented, including theories underlying $\mathrm{BPM}$ as well as short discussions from the literature on the benefits of BPM. This theoretical background will be followed by the explanation of the research methodology used to create a taxonomy. The research results obtained will then be presented specifically as an initial taxonomy. Finally, the contribution and limitations of the study will be assessed and the direction of future research proposed.

\section{RESEARCH BACKGROUND}

\section{Theories underlying BPM motivations}

Theories and frameworks used for explaining BPM can help identify potential motivations and related goals to achieve through the use of BPM. Starting from the roots of process-based management concepts, we can point out two main perspectives in looking at BPM and the expected outcomes of its adoption: the organizational perspective and the technological perspective. For the organizational perspective, research and practice were focused on using process thinking during the design and improvement of an organization [8-10]. The technological perspective was

This work was supported by the Polish National Science Centre, Poland, Grant No. 2017/27/B/HS4/01734 
addressed by using process-based concepts and tools to support the design and implementation of IT systems [11, 12].

An integrated and interdisciplinary BPM framework was proposed by $[13,14]$, who indicated six core BPM elements required for the holistic and sustainable use of process management. These include strategic alignment, governance, methods, information technology, people and culture. Further studies on BPM also began to emphasize the importance of the contextual and environmental factors for BPM adoption $[15,16]$. As the BPM concept became more established, the list of potential expected benefits of BPM adoption expended. Motivational factors could also be driven by customers, suppliers, competitors and legal pressures exerted on organizations [16, 17].

To explain BPM phenomena in an organization, the BPM literature indicates mostly theories, which we also present in this study as the main theories underlying BPM adoption and enhancing understanding of BPM motivations [18, 19].

The technology-task fit theory is mainly used in the field of Information Systems and explains the relationship between processes and technology. According to this theory, benefits from the implementation and use of IT systems in organizations can be gained if the information system fits the tasks that need to be performed [20]. This theory can explain motivational factors related to the use of technology. The dynamic capabilities theory refers to the purposeful adaptation of organizational resources and competencies in the continual improvement process to respond better to a changing environment [21]. The contingency theory points to the situational fit between the method of organizing and managing and the environment in which the organization operates [22, pp. 96-100]. Thus, the contingency theory explains the aspect of environmental motivations which are forced by the external environment.

To enhance the understanding of BPM phenomena the theories referred to above should be synthesized [19, 23]. This integrated approach can serve as a common platform for developing a comprehensive theory explaining BPM.

\section{Motivations as benefits drivers}

The adoption of any new approach or organizational change like BPM is an effort for an organization. This effort must be justified by the expected benefits that should result from the investment of its effort. Therefore, studying factors that motivate organizational change, including BPM adoption, should consider the analysis of the perceived organizational benefits of the implemented change [2, 24, 25].

We propose to discuss the connection between the set of motivations and goals and the set of outcomes and benefits. We understand the term "benefit" as the desirable and measurable outcome of BPM implementation, where outcomes are "the goals a company realized". We understand the goals as "something a company desires to achieve" [24], whereas motivations are primary reasons that inspire an organization to adopt BPM. The connecting elements between the two aforementioned sets are planned activities.
We can formulate the following chain of connections that explain why an organization's motivations should be studied: Motivations $\rightarrow$ Goals $\rightarrow$ Activities $\rightarrow$ Outcomes $\rightarrow$ Benefits

The study of Malinova et al. [24] explains an important relationship between the goals articulated for a BPM initiative and its actual outcomes and benefits. The vehicle that delivers outcomes inspired by the goals is a set of activities that a company undertakes within the scope of a BPM initiative.

The expectation of benefits may encourage decision makers to give support to a BPM initiative in their organization and would shape their expectations as to what can be achieved with it. On the basis of these expectations, combined with their assessment of current organizational needs, the goals of a BPM initiative are formulated. Depending on the general goal of a BPM initiative a different approach to its realization could be taken - a more centralized, top-down approach focused on managing few processes at the time, or, a decentralized approach with multiple distributed initiatives relying more on a dynamic organizational social system. We can, therefore, conclude that knowledge of the initial motivations of BPM will contribute to the success of the undertaking initiative.

\section{Methodology}

\section{On-line cases collection and coding}

In order to collect data for our analysis we searched for published on-line BPM cases and success stories using the following search strings:

- Search string I ("Business Process Management” OR "BPM" AND "case study")

- Search string II ("Business Process Management" OR "BPM" AND "success story")

The collected cases were used as secondary data [26]. As this study is preliminary, we limited the number of stories by choosing recurring websites in both search strings and diversified them by choosing three websites of BPM suites vendors and three websites of BPM consulting companies. In total, 75 BPM case studies were used to propose an initial taxonomy. Due to the fact that proposed taxonomy can be further developed and we do not present the results of quantitative research, we believe that this sample is sufficient to present the study in progress.

In the first step of the analysis, in each case, we identified excerpts that offered reasons why the organization decided to adopt BPM. We identified 271 individual items of motivation which were subsequently coded based on descriptive datacoding canon [27]. We used NVivo software to support the coding process and analysis of qualitative data.

\section{Taxonomy development process}

We applied the methodology for taxonomy development by Nickerson et al. [6] and according to this study, we determined the meta-characteristic of motivations as the most comprehensive, based on theories underlying BPM adoption. We used three main characteristics as the basis: motivation 
driven by an organization, by technology, and by the environment. The further development of taxonomy, therefore, be based on this conceptual pillar.

Due to the current lack of useful classifications of BPM motivation in the literature, we elected to use the mixed conceptual/empirical approach to taxonomy development [6]. We employed an empirical approach using coding canon to row data i.e., descriptions of motivations identified in each case. Subsequently, we coded and classified similar data under the same category using a deductive method of conceptualizing of data.

We made every effort to meet the qualitative conditions for taxonomy, which should be concise, robust, comprehensive, extendible, and explanatory [6]. However, the number of dimensions and the number of motivations can be extended in future research, so our preliminary taxonomy may be less than comprehensive.

\section{RESULTS}

According to the used methodology [6], we identified three main dimensions to develop this initial taxonomy of BPM motivations. Based on BPM knowledge, we proposed characteristics for each dimension.

Analyzing the BPM literature on objectives, outcomes and the overall benefits of BPM, we noticed that they are formulated at different organizational levels. At the 'macro' level of the organization they refer to the overall effectiveness, strategy, organizational structures, methods of allocation and utilization of resources, etc. At the level of processes, the goals and outcomes often refer to one or few more processes or the phases of the process life cycle, such as process design, analysis, redesign, implementation, monitoring and controlling [24]. Occasionally, the formulation of goals and expected benefits is focused on even more specific elements such as work positions and relate to tasks. A good example of such a situation may be the formulation of goals for the recently popular Robotic Process Automation applications where outcomes are expected at task or process levels [28]. Although it is obvious that all achieved results translate into the effectiveness of the entire organization [9], focusing the motivation either on the entire organization or process, or task will indicate the scope and complexity of planned organizational changes. For this reason, we decided to highlight the scope characteristics and three levels of impact within the 'Organization' dimension.

When planning the second dimension, 'Technology', we took into account the long-term relationship of the applied process approach with the implementation and use of information technology, which was also highlighted by us in the background of this study. We have, therefore, decided to examine to what extent the motivations for adopting BPM are inspired by technology.

In the third dimension, 'Environment', our intention was to check whether it is the internal or external environment that motivates decisions regarding BPM adoption more often. The internal environment is shaped mainly by the organization's owners, the board of directors, employees and organizational culture. However, BPM initiatives may also be triggered by

TABLE I.

INITIAL TAXONOMY OF BPM MOTIVATIONS

\begin{tabular}{|c|c|c|c|c|c|c|c|}
\hline \multirow[b]{2}{*}{ Examples of coded motivations } & \multicolumn{3}{|c|}{$\begin{array}{l}\text { Motivations related to the scope of the BPM } \\
\text { initiative in an Organization }\end{array}$} & \multicolumn{2}{|c|}{$\begin{array}{l}\text { Motivations related to the } \\
\text { use of Technology }\end{array}$} & \multicolumn{2}{|c|}{$\begin{array}{l}\text { Motivations driven by } \\
\text { Environment }\end{array}$} \\
\hline & $\begin{array}{c}\text { Motivations } \\
\text { driven at the } \\
\text { organizations } \\
\text { level }\end{array}$ & $\begin{array}{c}\text { Motivations } \\
\text { driven at } \\
\text { the process } \\
\text { level }\end{array}$ & $\begin{array}{c}\text { Motivations } \\
\text { driven at the } \\
\text { task level }\end{array}$ & $\begin{array}{c}\text { Techno- } \\
\text { logical } \\
\text { motivations }\end{array}$ & $\begin{array}{l}\text { Non techno- } \\
\text { logical } \\
\text { motivations }\end{array}$ & $\begin{array}{c}\text { Internal } \\
\text { environment } \\
\text { driven } \\
\text { motivations }\end{array}$ & $\begin{array}{c}\text { External } \\
\text { environment } \\
\text { driven } \\
\text { motivations }\end{array}$ \\
\hline Clarify roles and responsibilities & $\mathrm{x}$ & & & & $\mathrm{x}$ & $\mathrm{x}$ & \\
\hline Improve governance mechanisms & $\mathrm{x}$ & & & & $\mathrm{x}$ & $\mathrm{x}$ & \\
\hline $\begin{array}{l}\text { Comply with new regulatory } \\
\text { requirements }\end{array}$ & $\mathrm{x}$ & & & & $\mathrm{x}$ & & $\mathrm{x}$ \\
\hline Capture organizational knowledge & $\mathrm{x}$ & & & & $\mathrm{x}$ & $\mathrm{x}$ & \\
\hline Respond to customer requirements & $\mathrm{x}$ & & & & $\mathrm{x}$ & & $\mathrm{x}$ \\
\hline $\begin{array}{l}\text { Improve collaboration in an } \\
\text { organization }\end{array}$ & $\mathrm{x}$ & & & & $\mathrm{x}$ & $\mathrm{x}$ & \\
\hline Eliminate process errors & & $\mathrm{x}$ & & & $\mathrm{x}$ & $\mathrm{x}$ & \\
\hline Reduce process costs & & $\mathrm{x}$ & & & $\mathrm{x}$ & $\mathrm{x}$ & \\
\hline Improve financial performance & $\mathrm{x}$ & & & & $\mathrm{x}$ & $\mathrm{x}$ & \\
\hline Improve process efficiency & & $\mathrm{x}$ & & & $\mathrm{x}$ & $\mathrm{x}$ & \\
\hline Reduce manual tasks & & & $\mathrm{x}$ & $\mathrm{x}$ & & $\mathrm{x}$ & \\
\hline Automate tasks & & & $\mathrm{x}$ & $\mathrm{x}$ & & $\mathrm{x}$ & \\
\hline Implement new IT system & $\mathrm{x}$ & & & $\mathrm{x}$ & & $\mathrm{x}$ & \\
\hline $\begin{array}{l}\text { Improve data and information } \\
\text { quality }\end{array}$ & & $\mathrm{x}$ & & & $\mathrm{x}$ & $\mathrm{x}$ & \\
\hline
\end{tabular}


pressure from the external environment such as customers, suppliers or changes in regulations [23].

Table I presents the initial taxonomy of BPM adoption. In the first column we present the examples of encoded motivations from our study in order to show that, following the used methodology, at least one motivation is classified under every characteristic of every dimension. Such a taxonomy, according to qualitative attributes, is extensible and explanatory [6]. Therefore, can be extended in future studies.

\section{V.CONCLUDING REMARKS, LIMITATIONS AND FUTURE RESEARCH}

It seems obvious that organizations are motivated to adopt BPM by the desire to achieve expected benefits. However, the primary motivations for this adoption remained unexplored until the results of this study were presented. Our research is the first attempt to identify and categorize the initial reasons that grounded the decision on the adoption of BPM. Our research contributes to the theory by offering the firs methodologically developed taxonomy of BPM motivation.

We believe that our research will contribute to inspiring organizations and dispelling their possible doubts about the benefits of adopting BPM.

We also acknowledge some limitations of our study. Firstly, it might be the case that success stories published on vendors' websites tend to describe cases with only positive effects of BPM application. Secondly, the investigated cases described the effects of various process initiatives without distinguishing between one-time improvement projects and initiatives that are a part of a systematic approach to BPM adoption that could enable ongoing process-based management of an organization. Motivations for these types of projects may have different dynamics.

In future studies, we plan to extend the sample of success stories. Based on classified motivations, we intend to develop motivation patterns that will include groups of motivating factors and organization characteristics. Finally, we plan to investigate how the various types of motivations impact the future success or failure of BPM initiatives.

\section{REFERENCES}

[1] Rudden, J.: Making the case for BPM: a benefits checklist. BPTrends (2007)

[2] Malinova, M., Mendling, J.: A qualitative research perspective on BPM adoption and the pitfalls of business process modeling. In: La Rossa, M., Soffer, P. (eds.) Business Process Management Workshops, vol. LNBIP 132, pp. 77-88. Springer, Berlin-Heidelberg (2013)

[3] Moon, M.J.: Organizational Commitment Revisited in New Public Management: Motivation, Organizational Culture, Sector, and Managerial Level. Public Performance \& Management Review 24, 177-194 (2000). https://doi.org/10.2307/3381267

[4] Paarlberg, L.E., Lavigna, B.: Transformational leadership and public service motivation: Driving individual and organizational performance. Public Administration Review 70, $710-718$ (2010) https://doi.org/10.1111/j.1540-6210.2010.02199.x

[5] Haque, M.F., Haque, M.A., Islam, M.: Motivational Theories-A Critical Analysis. ASA University Review 8, 61-68 (2014)

[6] Nickerson, R.C., Varshney, U., Muntermann, J.: A method for taxonomy development and its application in information systems.
European Journal of Information Systems 22, 336-359 (2013) https://doi.org/10.1057/ejis.2012.26

[7] Bailey, K.D.: Typologies and taxonomies. An Introduction to classification Techniques. Sage, Thousand Oaks CA (1994)

[8] Hammer, M., Champy, J.: Reengineering the Corporation. A Manifesto for Business Revolution. Harper Business (1993)

[9] Rummler, G.A., Brache, A.P.: Improving performance: how to manage the white space on the organization chart. Jossey-Bass (1995)

[10] McCormack, K.P., Johnson, W.C.: Business Process Orientation. Gaining the E-Business Competitive Advantage. CRC Press (2001)

[11] Scheer, A.-W., Jost, W.E.: ARIS in der Praxis. Gestaltung, Implementierung und Optimierung von Geschäftsprozessen. Springer, Berlin, Heidelberg (2002)

[12] Van der Aalst, W.M.P., Ter Hofstede, A.H.M., Weske, M.: Business Process Management: A Survey. In: van der Aalst, W.M.P., Weske, M. (eds.) Business Process Management., vol. LNCS 2678, pp. 1-12. Springer, Berlin, Heidelberg (2003)

[13]De Bruin, T., Rosemann, M.: Towards a Business Process Management Maturity Model. In: Bartmann, D., Rajola, F., Kallinikos, J., Avison, D., Winter, R., Ein-Dor, P., al., e. (eds.) Proceedings of the Thirteenth European Conference on Information Systems, 26-28 May 2005, Germany, Regensburg (2005)

[14]Rosemann, M., Vom Brocke, J.: The six core elements of Business Process Management. In: vom Brocke, J., Rosemann, M. (eds.) Handbook on Business Process Management 1, pp. 105-122. Springer (2015)

[15] Vom Brocke, J., Zelt, S., Schmiedel, T.: On the role of context in Business Process Management. International Journal of Information Management 36, 486-495 (2016) https://doi.org/10.1016/j.ijinfomgt.2015.10.002

[16] Gabryelczyk, R., Roztocki, N.: Business Process Management success framework for transition economies. Information Systems Management 35, 234-253 (2018) https://doi.org/10.1080/10580530.2018.1477299

[17] Willaert, P., Van Den Bergh, J., Willems, J., Deschoolmeester, D.: The process-oriented organisation: a holistic view developing a framework for business process orientation maturity. In: G., A., P., D., M., R. (eds.) Business Process Management, vol. LNCS 4714, pp. 1-15. Springer (2007)

[18] Van Looy, A., Van den Bergh, J.: The Effect of Organization Size and Sector on Adopting Business Process Management. Business \& Information Systems Engineering 60, 479-491 (2018)

[19]Trkman, P.: The Critical Success Factors of Business Process Management. International Journal of Information Management 30, 125 134 (2010) https://doi.org/10.1016/j.ijinfomgt.2009.07.003

[20]Furneaux, B.: Task-Technology Fit Theory: A Survey and Synopsis of the Literature. In: Dwivedi, Y.K., Wade, M.R., Schneberger, S.L. (eds.) Information Systems Theory: Explaining and Predicting Our Digital Society, Vol. 1, pp. 87-106. Springer New York, New York, NY (2012)

[21] Teece, D.J., Pisano, G., Shuen, A.: Dynamic capabilities and strategic management. Strategic Management Journal 18, 509-533 (1997)

[22] Scott, R.W.: Organizations. Rational, Natural, and Open Systems. Prentice Hall, New Jersey (2003)

[23] Gabryelczyk, R.: Exploring BPM Adoption Factors: Insights into Literature and Experts Knowledge. In: Ziemba, E. (ed.) Information Technology for Management: Emerging Research and Applications, vol. LNBIP 346, pp. 155-175. Springer International Publishing, Cham (2019)

[24] Malinova, M., Hribar, B., Mendling, J.: A framework for assessing BPM success. Proceedings of the 22nd European Conference on Information Systems. Association for Information Systems, Tel Aviv, Israel (2014)

[25]Tuček, D.: The Main Reasons for Implementing BPM in Czech Companies. Journal of Competitiveness 7, 126-142 (2015)

[26] Poba-Nzaou, P., Uwizeyemungu, S., Raymond, L., Paré, G.: Motivations underlying the adoption of ERP systems in healthcare organizations: Insights from online stories. Information Systems Frontiers 16, 591-605 (2012)

[27] Saldana, J.: The Coding Manual for Qualitative Researchers. Sage, Los Angeles, London (2013)

[28]Houy, C., Hamberg, M., Fettke, P.: Robotic Process Automation in Public Administrations. In: Räckers, M., Halsbenning, S., Rätz, D., Richter, D., Schweighofer, E. (eds.) Digitalisierung von Staat und Verwaltung, pp. 62-74. Gesellschaft für Informatik eV, Bonn (2019) 